\title{
Welcome to Minerals and Mineral Materials, a new scientific and technological journal
}

\author{
Shaoxian Song \\ School of Resources and Environmental Engineering, Wuhan University of Technology, Wuhan 430070, Hubei, China.
}

Correspondence to: Prof. Shaoxian Song, School of Resources and Environmental Engineering, Wuhan University of Technology, Luoshi Road 122, Wuhan 430070, Hubei, China. E-mail: ssx851215@whut.edu.cn

How to cite this article: Song S. Welcome to Minerals and Mineral Materials, a new scientific and technological journal. Miner Miner Mater 2021;1:1. https://dx.doi.org/10.20517/mmm.2021.01

Received: 7 Oct 2021 Accepted: 8 Oct 2021 Available online: 15 Oct 2021

Academic Editor: Shaoxian Song Copy Editor: Xi-Jun Chen Production Editor: Xi-Jun Chen

Today, the global minerals industry is facing its greatest challenge because of the increasing needs for raw materials, pressing environmental concerns, and growing effects of global climate change. On the one hand, declining ore grade and quality, increasing ore complexity and variability, and decreasing particle size due to finely disseminated minerals has led the mineral beneficiation to be of much lower efficiency or to be unfeasible in economies; but on the other hand, market and policy of minerals require that mineral products be concentrates of higher grades and lower impurities and have less environmental impacts. In this pressing situation, scientists and engineers in mineral processing must explore innovative technological solutions in order to make the mineral resources production sustainable in development and be environmentally responsible. The solutions will mainly rely upon the enormous amount of research, both scientific and technological, developing new processes, new equipment, and new chemical reagents.

In addition, mineral-based materials are widely used as construction materials or functional materials. They feature low costs and eco-friendly characteristics, and are applied to many fields, both traditional and advanced. The traditional applications, for example, rutile as pigment in paint industry and kaolin as filler in paper industry, lead to the annual productions of thousands of millions tonnage of mineral materials. The advanced applications are direct to the fields of new energy, electronics, medicine, biology, and many more. In the past two decades, several research hotspots such as graphene, molybdenum disulfide, and perovskite, have been related to the processing and modification of mineral as materials, showing that

The Author(s) 2021. Open Access This article is licensed under a Creative Commons Attribution 4.0 International License (https://creativecommons.org/licenses/by/4.0/), which permits unrestricted use, sharing, adaptation, distribution and reproduction in any medium or format, for any purpose, even commercially, as long as you give appropriate credit to the original author(s) and the source, provide a link to the Creative Commons license, and indicate if changes were made. 
natural minerals would have great potentialities to be advanced materials. It is believed that mineral materials will find more and new applications in the recent future, and thus mineral production will greatly increase.

Here, it is my great pleasure to introduce this new open access journal, Minerals and Mineral Materials. The objective of launching this journal is to provide a new and good platform for the scientific and industrial communities of mineral processing and mineral materials to share and exchange the newest research results, innovative ideas, and interesting findings. Besides research papers, short communications, reviews, perspectives, and mini-reviews will also be considered for the publications. The research works on the whole chain of the mineral industry, from ore comminution to element extraction or direct mineral applications, are welcome to be submitted for the consideration of publication. Areas of interest include but are not limited to ore crushing, ore grinding, size classification, mineral concentration (e.g., flotation, magnetic separation, and gravity concentration), dewatering, wastewater treatment, waste solid managements, mine remediation, extractive metallurgy, powder preparation and modification, minerals nanoparticles, two dimensional mineral materials, and porous mineral materials. Also, research papers on artificial intelligence and online analysis systems applied to the mineral industry are welcome.

Innovative minerals technologies strongly depend on the better understandings of scientific mechanism in chemistry, physics, physical chemistry, and biology. Papers on fundamental study related to minerals are especially welcome. Additionally, the endeavors would be also encouraged on interdisciplinary success, especially for the preparation and applications of functional mineral materials.

Minerals and Mineral Materials will be published quarterly with additional special issues focusing on specific topics. We will carry out a strict peer review and obey standardized criteria for acceptance, both of scientific excellence and originality. We hope that Minerals and Mineral Materials will be a high-impact and reputational journal in the mineral community in the recent future.

As the first issue is launching, I would like to thank colleagues from the across world to form the editorial board. Their participation will certainly help this journal move on the right road and reach its goals smoothly. Also, thanks are due to the manager, managing editor, and technical personals of the OAE Publishing Inc. for the launching of this new journal.

\section{DECLARATIONS}

Authors' contributions

Wrote and reviewed the manuscript: Song $\mathrm{S}$

\section{Availability of data and materials}

Not applicable.

\section{Financial support and sponsorship}

None.

\section{Conflicts of interest}

The author declared that there are no conflicts of interest.

\section{Ethical approval and consent to participate}

Not applicable. 


\section{Consent for publication}

Not applicable.

\section{Copyright}

(c) The Author(s) 2021. 